\title{
Recombinant luteinizing hormone supplementation in women undergoing in vitro fertilization/ intracytoplasmic sperm injection with gonadotropin releasing hormone antagonist protocol: a systematic review and meta-analysis
}

\author{
Yujing Xiong ${ }^{\dagger}$, Zhiqin Bu ${ }^{\dagger}$, Wei Dai, Meixiang Zhang, Xiao Bao and Yingpu Sun ${ }^{*}$
}

\begin{abstract}
The objective of this meta-analysis is to assess the impact of LH supplementation in women undergoing in vitro fertilization/ intracytoplasmic sperm injection (IVF/ICSI) with gonadotropin releasing hormone (GnRH) antagonist protocol. No significant difference in outcomes between LH supplementation and r-FSH alone in women undergoing IVF/ICSI with GnRH antagonist protocol is currently present, and further studies are necessary for more solid conclusions on pregnancy likelihood to be drawn.
\end{abstract}

Keywords: Recombinant FSH, Recombinant LH, Ovarian stimulation, Meta-analysis, Oral contraceptive pills

\section{Background}

Compared to GnRH agonists which dominate in the area of assisted reproductive technology(ART) accounting for its essential role in circumventing the problem of a premature luteinizing hormone ( $\mathrm{LH}$ ) surge since the mid1980s, GnRH antagonists generate a prompt suppression of gonadotrophin release, but do not cause the flare-up effect, by specifically blocking the GnRH receptors and ultimately induce a decrease in serum LH levels and a less pronounced decrease in FSH secretion [1]. However, it is unpredictable whether or not $\mathrm{GnRH}$ antagonists cause a decline in serum oestradiol during follicular recruitment which would result in an adverse effect on the pregnancy outcome [2]. On the other hand, GnRH antagonists tend to oversuppress endogenous $\mathrm{LH}$ if the dosage or timing of use was not appropriately controlled. As it is reported that endogenous low level of LH influences detrimentally both on the development of normal healthy follicles, because growing follicles become increasingly sensitive to and finally dependent on $\mathrm{LH}$ for

\footnotetext{
* Correspondence: syp2008@vip.sina.com

${ }^{\dagger}$ Equal contributors

Reproductive Medical Centre, the First Affiliated Hospital of Zhengzhou University, Zhengzhou, Henan Province, China
}

their development [3], and on the endometrium after ovulation because sufficient LH is indispensable for the resumption of meiosis and for the production of progesterone. Therefore, it seems urgent for clinical doctors to add exogenous LH while GnRH antagonist protocol is applied to pituitary down-regulation in case of adverse effect on the pregnancy outcomes.

Nevertheless, there still has been no ultimate conclusion about the effect of r-LH supplementation to r-FSH in GnRH antagonist protocol on the pregnancy outcomes according to the recent studies. The issue on LH supplementation in women undergoing IVF/ICSI with GnRH antagonist for pituitary down-regulation has caused a heated debate around the world [4]. The studies by Sauer et al. (2004), Griesinger et al. (2005), Levi-Setti et al. (2006) did not demonstrate any beneficial effect of LH supplementation on the oocytes quality and the pregnancy outcomes [5-7], while two randomized trials have shown higher pregnancy rates among those receiving $\mathrm{rLH}$ with GnRH agonist protocol $[8,9]$. It is noticeable that the meta-analysis published in 2007 and 2010 separately showed no advantage in combination of r-LH with r-FSH in women undergoing IVF/ICSI with $\mathrm{GnRH}$ antagonist protocol compared with $\mathrm{r}$-FSH alone 
group $[10,11]$. Given this background, the issue in this area warrants further research [12].

A recent systemic review and meta-analysis concluded that the combination of r-hLH with r-FSH stimulation enhanced the clinical pregnancy and implantation rates in patients aged $\geq 35$ [13]. Similar results were reported in an open-label randomized controlled study by Bosch et al. (2011) which found that $\mathrm{r}-\mathrm{LH}$ is beneficial in improving the implantation rate in women aged 36-39 years [14], although König et al. (2013) argued that the pretreatment with hormonal contraceptives before stimulation and the LH supplementation on stimulation day 1 , while in his randomized controlled trial LH supplementation was given on stimulation day 6, might play an essential role in the discrepancy between two studies [15]. Until now, there has been no meta-analysis to review whether the LH supplementation benefits the advanced reproductive aged patients undergoing IVF/ICSI with GnRH antagonist protocol.

$\mathrm{GnRH}$ antagonist protocol depends on the occurrence of spontaneous menses, which is different from long $\mathrm{GnRH}$ agonist protocol in which ovarian stimulation can be initiated after pituitary desensitization has been achieved $[16,17]$. Therefore, pretreatment with oral contraceptive pill (OCP) before stimulation was applied in order to prevent ovarian cysts, for the sake of synchronous follicular development and predictingtiming events in an IVF/ ICSI cycle regarding scheduling [18]. In the studies by Sauer et al. (2004), Levi-Setti et al. (2006), Bosch et al. (2011), the patients were pretreated with OCP and used the GnRH antagonist protocol for $\mathrm{COH}$, but no special benefits was shown in $r-\mathrm{LF}+\mathrm{r}-\mathrm{FSH}$ group compared with the $\mathrm{r}-\mathrm{FSH}$ only group $[6,7,14]$. Consequently, it is necessary to explore whether combination of r-LH with r-FSH for $\mathrm{COH}$ benefits the pregnancy outcomes in women undergoing IVF or ICSI-ET with GnRH antagonist protocol and oral contraceptive pills pretreatment by meta-analysis.

Based on the above considerations, the present metaanalysis was performed to answer the questions: (1) whether combination of $\mathrm{r}-\mathrm{LH}$ with $\mathrm{r}-\mathrm{FSH}$ for $\mathrm{COH}$ benefits the pregnancy outcomes in general women undergoing IVF/ICSI with GnRH antagonist protocol;(2) whether combination of r-LH with $\mathrm{r}$-FSH for $\mathrm{COH}$ benefits the pregnancy outcomes in advanced reproductive aged women undergoing IVF/ICSI with GnRH antagonist protocol; (3) whether combination of $\mathrm{r}-\mathrm{LH}$ with $\mathrm{r}-\mathrm{FSH}$ for $\mathrm{COH}$ benefits the pregnancy outcomes in women undergoing IVF/ICSI with GnRH antagonist protocol and pretreated with oral contraceptive pills.

\section{Methods}

\section{Systematic search and strategy}

A systemic search of the relevant literature was performed without language limitation but restricted to randomized controlled trials (RCTs). We mainly explored MEDLINE, EMBASE, Web of science and Cochrane Library for the relevant studies about the effect of combination of r-LH with r-FSH for $\mathrm{COH}$ in patients undergoing IVF/ICSI with GnRH-antagonist protocol on IVF/ICSI outcomes. The following search strategy was used: ("luteinizing hormone" or "recombinant luteinizing hormone" or "lh" or "r-LH" or "hlh" or "recombinant lh" or "ovarian stimulation" or "recombinant FSH" or "lutropin alfa" or "recombinat human LH") AND ( "GnRH antagonist") AND ("assisted reproductive techniques" or "ART" or "IVF" or "ICSI" or "in vitro fertilization"or "intracytoplasmic sperm injections") AND ("randomized controlled trial " or "clinical trial" or "multicenter study" or "controlled study" or "double blind procedure" or "single blind procedure").

\section{Inclusion and exclusion criteria}

Inclusion criteria were RCTs that compared the effect of recombinant follicle-stimulating hormone (r-FSH) alone and combination with recombinant luteinizing hormone $(\mathrm{r}-\mathrm{LH})$ in women undergoing IVF/ICSI with $\mathrm{GnRH}$ antagonist protocol on IVF/ICSI outcomes. Exclusion criteria included failure to report appropriate randomization procedures, participants as poor responders, or outcomes unclear or inappropriate.

\section{Data extraction}

Studies were screened by two reviewers (Y.X. and Z.B.) independently and any disagreement was solved unanimously by discussion. Firstly, all titles and abstracts from the databases were examined, but only those with the possibility of meeting the predefined criteria were kept for further evaluation. Secondly, final inclusion decisions were made on examination of the full manuscripts. If the published study was judged to contain

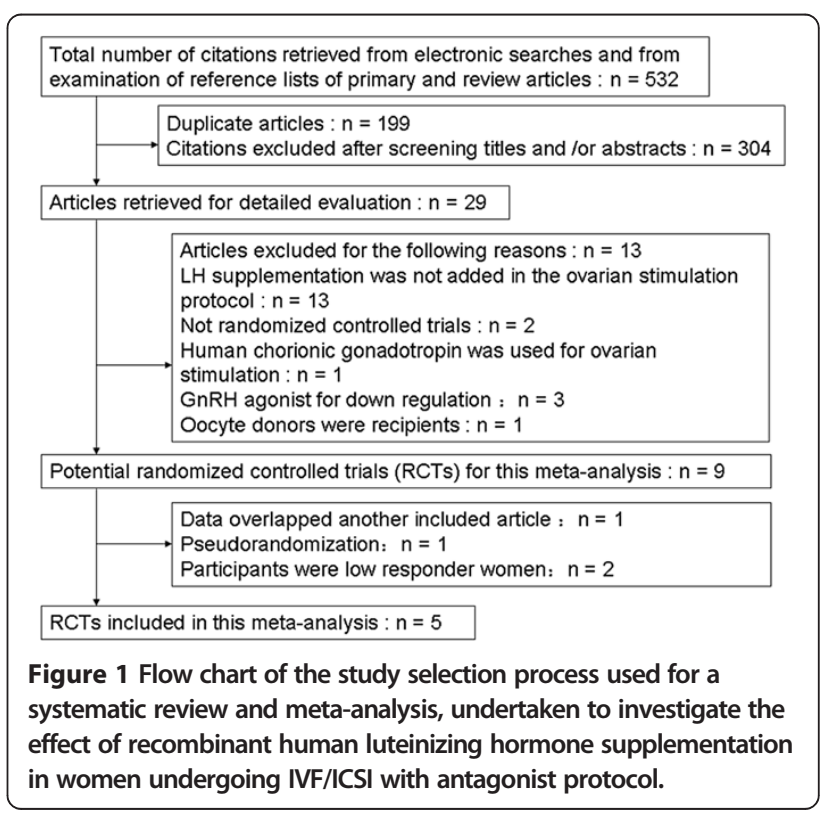


Table 1 Characteristics of included studies

\begin{tabular}{|c|c|c|c|c|c|c|}
\hline $\begin{array}{l}\text { Included } \\
\text { RCTs }\end{array}$ & $\begin{array}{l}\text { Method of } \\
\text { randomization }\end{array}$ & $\begin{array}{l}\text { Number of patients } \\
\text { (rLHtrFSH/rFSH) }\end{array}$ & $\begin{array}{l}\text { Gn type and initial } \\
\text { dosage (IU/d) }\end{array}$ & rLH protocol & Pretreament & $\begin{array}{l}\text { Primary } \\
\text { outcomes }\end{array}$ \\
\hline \multirow[t]{2}{*}{$\begin{array}{l}\text { Sauer } \\
\text { et al. } 2004 \text { [5] }\end{array}$} & \multirow[t]{2}{*}{$\begin{array}{l}\text { Computer } \\
\text { generated }\end{array}$} & \multirow[t]{2}{*}{$21 / 21$} & \multirow[t]{2}{*}{ r-hFSH 225} & \multirow[t]{2}{*}{$\begin{array}{l}\text { r-hLH, } 150 \text { IU on } \\
\text { stimulation day } 7-10\end{array}$} & \multirow{2}{*}{$\begin{array}{l}\text { Oral contraceptive pretretment } \\
\text { (0.15 mg desogestrel and } \\
0.03 \mathrm{mg} \text { ethinyloestradiol) }\end{array}$} & $\begin{array}{l}\text { Mean number } \\
\text { of retrieved }\end{array}$ \\
\hline & & & & & & MII oocytes \\
\hline $\begin{array}{l}\text { Griesinger } \\
\text { et al. } 2005 \text { [6] }\end{array}$ & Sealed envelop & $61 / 65$ & r-hFSH 150 & $\begin{array}{l}\text { rLH, } 75 \text { IU on day } 2 \text { of the } \\
\text { natural cycle }\end{array}$ & None & $\begin{array}{l}\text { Number of days } \\
\text { of gonadotropin } \\
\text { treatment }\end{array}$ \\
\hline $\begin{array}{l}\text { Levi-Setti et al. } \\
2006 \text { [7] }\end{array}$ & $\begin{array}{l}\text { Computer- } \\
\text { generated list }\end{array}$ & $20 / 20$ & r-hFSH 150 & $\begin{array}{l}\text { rLH, } 75 \text { IU when follicles } \\
\text { reached the mean } \\
\text { diameter of } 14 \text { and } \\
15 \mathrm{~mm}\end{array}$ & $\begin{array}{l}\text { Oral contraceptive ((Minulet; } \\
\text { Wyeth, Aprilia-Latinia, Italy)) }\end{array}$ & $\begin{array}{l}\text { Number of } \\
\text { metaphase II } \\
\text { oocytes } \\
\text { retrieved }\end{array}$ \\
\hline $\begin{array}{l}\text { Bosch } \\
\text { et al. } 2011 \text { [14] }\end{array}$ & $\begin{array}{l}\text { Computer- } \\
\text { generated list }\end{array}$ & $\begin{array}{l}\text { Aged }<35 \text { years:190/ } \\
190 ; \text { aged } 36 \text { to } \\
39 \text { years: } 170 / 170\end{array}$ & $\begin{array}{l}\text { Patients } \leq 35 \text { years old: rFSH-alone group: rFSH } 225 \text {; the rFSH } \\
\text { + rLH group: rFSH 150; patients aged } 36-39 \text { years: rFSH-alone } \\
\text { group: rFSH 300; rFSH + rLH group: rFSH } 225\end{array}$ & $\begin{array}{l}\mathrm{rLH}, 75 \mathrm{IU} \text { on stimulation } \\
\text { day } 1\end{array}$ & $\begin{array}{l}\text { Oral contraceptive pill } \\
\text { ( } 0.030 \mathrm{mg} \text { ethinyl E2 and } \\
3.0 \mathrm{mg} \text { drospirenone) }\end{array}$ & $\begin{array}{l}\text { Implantation } \\
\text { rate }\end{array}$ \\
\hline $\begin{array}{l}\text { König et al. } \\
2013 \text { [15] }\end{array}$ & $\begin{array}{l}\text { Sealed } \\
\text { envelopes }\end{array}$ & $125 / 128$ & r-hFSH, $225 \mathrm{IU}$ & $\begin{array}{l}\text { rLH, } 150 \text { IU on stimulation } \\
\text { day } 6\end{array}$ & None & $\begin{array}{l}\text { Implantation } \\
\text { rate; clinical } \\
\text { pregnancy rate }\end{array}$ \\
\hline
\end{tabular}




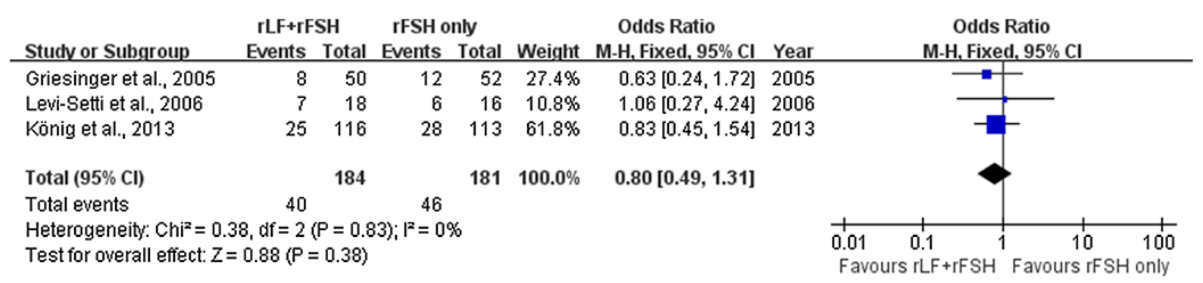

Figure 2 Forest plot of ongoing pregnancy per ET with or without $\mathrm{r}$-LH supplementation for $\mathrm{COH}$ in general population undergoing IVF or ICSI-ET with GnRH antagonist protocol.

insufficient information, study authors were contacted. The following data were recorded from each of the studies: methodologic (randomization method)was declared, number of patients included $(\mathrm{rLH}+\mathrm{rFSH} / \mathrm{rFSH})$, inclusion criteria, ovarian stimulation protocol, Gn type and initial dosage (IU/d), Gn type and initial dosage (IU/d), rLH protocol, use of oral contraceptive pretreatment with and primary outcomes in each article.

\section{Outcome parameters}

The main outcome measure chosen for the current meta-analysis was ongoing pregnancy per ET (defined as the presence of fetal heart activity on ultrasound at 12 weeks of gestation per ET) and clinical pregnancy per ET. The primary adverse effect was OHSS. Secondary outcome measures included days of stimulation, amount of r-FSH dose used, number of retrieved oocytes per oocyte retrieval, number of mature oocytes (metaphase II) per oocyte retrieval, fertilization rate, implantation rate, serum oestrodial on $\mathrm{hCG}$ day $(\mathrm{pg} / \mathrm{ml})$, serum progesterone on hCG day (ng/ml).

\section{Quantitative analysis}

All results were combined for meta-analysis with Revman Software (Version 5, The Cochrane Collaboration, 2003). Continuous variables were expressed as weighted mean difference (WMD) with 95\% confidence intervals (CIs). Dichotomous data for each unit of analysis were expressed as an odds ratio (OR) with 95\% CIs. Heterogeneity was evaluated using the Q-test and $\mathrm{I}^{2}$-index values, and reported for each outcome as a P-value and percentage, respectively. Bias was assessed at the study level using a qualitative review assessing randomization, double blinding, and withdrawals and dropouts. In the absence of statistical heterogeneity a summary estimate of the odds ratio with a $95 \%$ was calculated in a fixed-effect model using the Peto modification of the Mantel- Haenszel method. In case of significant statistical heterogeneity, we performed sensitivity analysis using the random-effect model. A P-value $<0.05$ was considered statistically significant.

\section{Results}

\section{Systematic review}

The search strategy retrieved a total of 532 references, 29 full text articles were reviewed, and from these 5 trials met full inclusion criteria $[5-7,14,15]$ and were included in the analysis with no disagreement noted between the reviewers responsible for study selection (Figure 1). Further details about these studies are provided in the Table 1. All the five trials were meta-analyzed to compare r-FSH combined with $\mathrm{r}-\mathrm{LH}$ versus r-FSH alone in $\mathrm{GnRH}$ antagonist protocols in the general population. Two trials were meta-analyzed to compare r-FSH combined with $\mathrm{r}$-LH versus $\mathrm{r}-\mathrm{FSH}$ alone in $\mathrm{GnRH}$ antagonist protocols in advanced reproductive aged women $[14,15]$. In addition, three trials were meta-analyzed to compare r-FSH combined with r-LH versus $r$-FSH alone in $\mathrm{GnRH}$ antagonist protocols in patients pretreated with oral contraceptive pills $[6,7,14]$.

\section{Meta-analysis}

Combination of $r-\mathrm{LH}$ with $\mathrm{r}-\mathrm{FSH}$ versus $\mathrm{r}-\mathrm{FSH}$ alone for $\mathrm{COH}$ in general population undergoing IVF or ICSI-ET with $\mathrm{GnRH}$ antagonist protocol.

\begin{tabular}{|c|c|c|c|c|c|c|c|c|}
\hline Study or Subgroup & $\begin{array}{l}\text { rLF+rFs } \\
\text { Events }\end{array}$ & $\begin{array}{l}\text { SH } \\
\text { Total }\end{array}$ & $\begin{array}{l}\text { rFSH or } \\
\text { Events }\end{array}$ & $\begin{array}{l}\text { nly } \\
\text { Total }\end{array}$ & Weight & $\begin{array}{c}\text { Odds Ratio } \\
\text { M-H, Fixed, } 95 \% \mathrm{Cl}\end{array}$ & Year & $\begin{array}{c}\text { Odds Ratio } \\
\text { M-H, Fixed, } 95 \% \mathrm{Cl}\end{array}$ \\
\hline Sauer et al., 2004 & 10 & 21 & 11 & 21 & $17.7 \%$ & $0.83[0.25,2.77]$ & 2004 & \\
\hline König et al., 2013 & 35 & 116 & 38 & 113 & $82.3 \%$ & $0.85[0.49,1.49]$ & 2013 & \\
\hline Total $(95 \% \mathrm{Cl})$ & & 137 & & 134 & $100.0 \%$ & $0.85[0.51,1.41]$ & & \\
\hline Total events & 45 & & 49 & & & & & \\
\hline \multicolumn{8}{|c|}{$\begin{array}{l}\text { Heterogeneity: } \text { Chi }^{2}=0.00, d f=1(P=0.96) ; I^{2}=0 \% \\
\text { Test for overall effect: } Z=0.64(P=0.52)\end{array}$} & $\begin{array}{ccccc} & 1 & 1 & 1 & + \\
0.02 & 0.1 & 1 & 10 & 50 \\
\text { Favours rLF+rFSH } & \text { Favours rFSH only }\end{array}$ \\
\hline
\end{tabular}

Figure 3 Forest plot of clinical pregnancy per ET with or without r-LH supplementation for $\mathrm{COH}$ in general population undergoing IVF or ICSI-ET with GnRH antagonist protocol. 


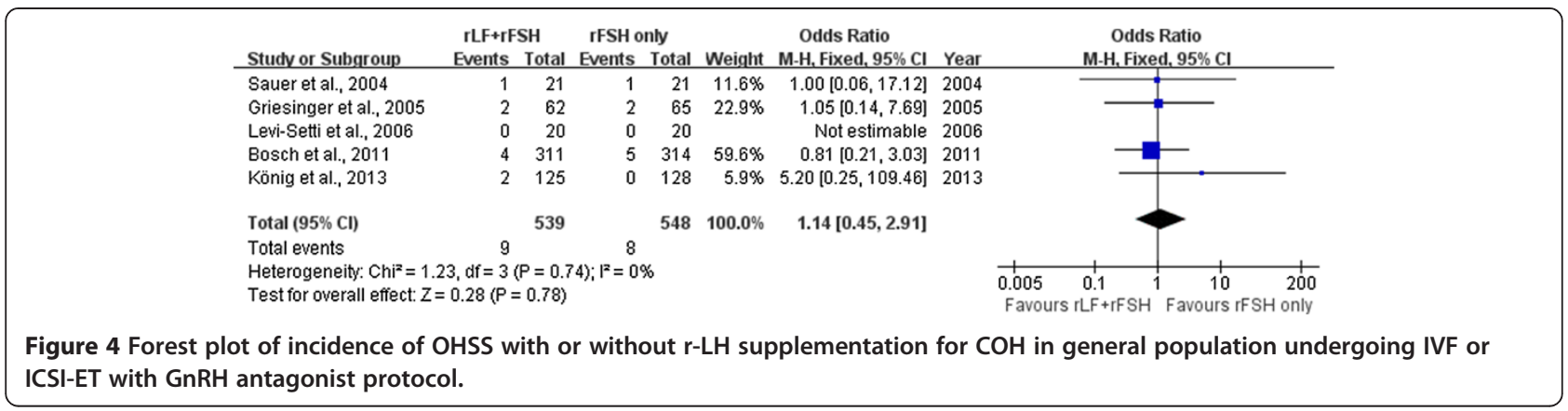

\section{Primary outcomes}

\section{Ongoing pregnancy per ET}

Three trials with a total of 365 embryo transfers provided data on the ongoing pregnancy per ET $[5,7,15]$. The pooled analysis with these three trials did not show differences between the r-LH supplementation group and the r-FSH alone group (three trials: OR 0.80; 95\% CI 0.49 to 1.31 ) and there was no indication of statistical heterogeneity (Figure 2).

\section{Clinical pregnancy per ET}

Two trials with a total of 271 embryo transfers provided data on the clinical pregnancy per ET $[6,15]$. The pooled analysis with these three trials did not show differences between the r-LH supplementation group and the r-FSH alone group (two trials: OR $0.90 ; 95 \%$ CI 0.65 to 1.42 ) and there was no indication of statistical heterogeneity (Figure 3).

\section{Incidence of ovarian hyperstimulation syndrome (OHSS)}

There was no evidence of a statistical difference in incidence of OHSS (five trials: OR 1.14, 95\% CI 0.45 to 2.91 ) and there was no indication of statistical heterogeneity (Figure 4).

\section{Secondary outcomes}

Four trials reported on serum progesterone level on hCG day $[5,7,14,15]$. Pooling the data resulted in a significantly higher serum oestradiol level (WMD 237.39, 95\% CI 134.58 to 340.20) (Figure 5) and lower serum progesterone level (WMD $-0.16,95 \%$ CI -0.22 to -0.10 ) in the $\mathrm{r}$ - $\mathrm{LH}$ supplementation group than in the $\mathrm{r}$-FSH alone group (Figure 6).

The data from the trials was pooled separately and there was no evidence of a statistical difference in $\mathrm{r}$-FSH total dose used per treatment cycle regarding r-FSH total dose used per treatment cycle (four trials: WMD -77.96, $95 \%$ CI -211.46 to 55.53$)$, total days of stimulation per treatment cycle (four trials: WMD $0.20,95 \%$ CI -0.37 to $0.76)$, number of retrieved oocytes per oocyte retrieval (four trials: WMD $0.58,95 \% \mathrm{CI}-1.27$ to 0.1 ), number of mature oocytes (metaphase II) per oocyte retrieved(two trials: OR 0.88 ; $95 \%$ CI 0.66 to 1.17 ), fertilization rate (two trials: OR1.03; 95\% CI 0.89 to 1.20 ) and implantation rate (three trials: OR 0.76 ; $95 \%$ CI 1.51 to 1.13 ).

Combination of $\mathrm{r}$ - $\mathrm{LH}$ with $\mathrm{r}$-FSH versus $\mathrm{r}$-FSH alone for $\mathrm{COH}$ in advanced reproductive aged women undergoing IVF or ICSI-ET with GnRH antagonist protocol rFSH total dose used per treatment cycle.

\section{r-FSH total dose used per treatment cycle}

Two trials reported data on $\mathrm{r}-\mathrm{FSH}$ dose used per treatment cycle $[5,14]$. There was a statistical difference in $r$ FSH total dose used per treatment cycle (two trials: WMD $-89.86,95 \%$ CI -96.59 to -83.13 ) (Figure 7).

\section{Serum oestrodial level on hCG day}

Two trials reported on serum oestradiol level on hCG day $[14,15]$. Pooling the data resulted in a significantly higher serum oestradiol level in the r-LH supplementation group than in the r-FSH alone group (WMD 245.46, 95\% CI 104.85 to 386.06 ) (Figure 8).

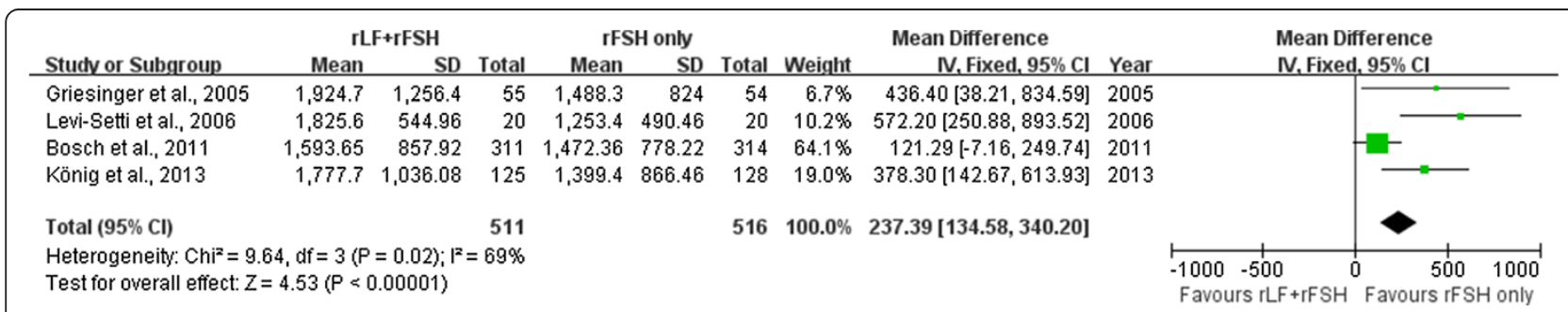

Figure 5 Forest plot of serum oestrodial level on hCG day with or without r-LH supplementation for COH in general population undergoing IVF or ICSI-ET with GnRH antagonist protocol. 


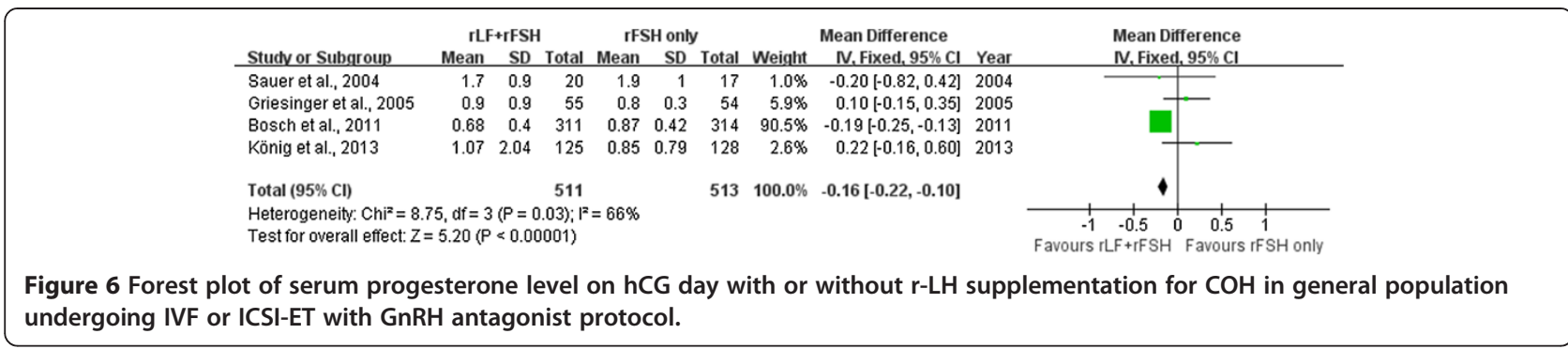

\section{Number of retrieved oocytes per oocyte retrieval}

Both of the two trials reported on the number of retrieved oocytes per oocyte retrieval $[14,15]$. Pooling the data showed a significantly higher number of retrieved oocytes per oocyte retrieval in the r-FSH alone group (two trials: WMD -1.3 , 95\% CI -2.29 to -0.32 ) (Figure 9).

\section{Other outcomes}

Pooling the data in the trials did not show a significant difference between the r-LH supplementation group and the r-FSH alone group regarding the total days of stimulation per treatment cycle (two trials: WMD -0.05 , 95\% CI -0.73 to 0.64 ), incidence of OHSS (three trials: OR $1.77,95 \% \mathrm{CI}$ 0.38 to 8.32 ), serum progesterone level on hCG day (WMD $-0.04,95 \%$ CI -0.46 to -0.38 ).

Combination of $\mathrm{r}$ - $\mathrm{LH}$ with $\mathrm{r}$-FSH versus $\mathrm{r}$-FSH alone for $\mathrm{COH}$ in women undergoing IVF or ICSI-ET with GnRH antagonist protocol and oral contraceptive pills pretreatment.

\section{Total days of stimulation per treatment cycle}

Two trials reported on the total days of stimulation per treatment cycle $[6,14]$. Pooling the data showed a significantly higher total days of stimulation per treatment cycle in the r-LH supplementation group than in the $\mathrm{r}$ FSH alone group (two trials: WMD 0.49, 95\% CI 0.12 to 0.85 ) and there was no indication of statistical heterogeneity (Figure 10).

\section{Serum progesterone level on hCG day}

Two trials reported on serum oestradiol and progesterone level on hCG day $[7,14]$. Pooling the data resulted in a significantly higher serum progesterone level in the $r-$ FSH alone group than in the r-LH supplementation group (WMD $-0.19,95 \% \mathrm{CI}-0.25$ to -0.13 ) (Figure 11 ).

\section{Other outcomes}

No evidence of a significant difference was found between the $\mathrm{r}$-LH supplementation group and the r-FSH alone group regarding incidence of ovarian hyperstimulation syndrome (OHSS) (three trials: OR 0.84, 95\% CI 0.25 to 2.78 ), r-FSH total dose used per treatment cycle (two trials: WMD -211.90 , 95\% CI -319.99 to -103.82), serum oestrodial level on hCG day (WMD 321.71, 95\% CI -117.44 to 760.86), number of retrieved oocytes per oocyte retrieval (two trials: WMD $-0.69,95 \% \mathrm{CI}-1.52$ to 0.13 ), r-FSH total dose used per treatment cycle (two trials: WMD -211.90, 95\% CI -319.99 to -103.82 ).

\section{Discussion}

Our systematic review and meta-analysis addressed the issue on the comparison of the outcomes between the combination of $\mathrm{r}$ - $\mathrm{LH}$ with $\mathrm{r}$-FSH and $\mathrm{r}$-FSH alone for $\mathrm{COH}$ in women undergoing IVF/ICSI with GnRH antagonist protocol and the comparisons in the subgroups of advanced reproductive aged women and women pretreated with oral contraceptive pills were also carried out.

Based on the "two-cell, two-gonadotropin" theory, the LH and FSH play a critical role in stimulating the two cellular components of ovary, which are theca cell and granulosa cell, leading to the production of ovarian steroids [19,20]. At the earlier stage of follicular development, FSH is indispensable for follicular growth and the formation of estrogen by inducing the aromatase enzyme converting androgen to estradiol [21], while the androgen production from cholesterol is dependent on the stimulation of the theca cells by $\mathrm{LH}$ and FSH together [22]. Although FSH can induce follicular growth even without $\mathrm{LH}$, there was identified that the follicles would have developmental deficiencies, following hCG administration [23], which suggested that the effect of LH on follicular development was probably not only due to

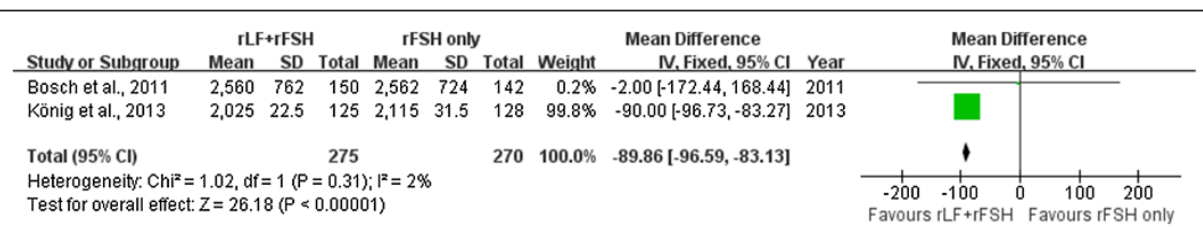

Figure 7 Forest plot of rFSH total dose used per treatment cycle with or without r-LH supplementation for COH in advanced reproductive aged women undergoing IVF or ICSI-ET with GnRH antagonist protocol. 


\begin{tabular}{|c|c|c|c|c|c|c|c|c|c|}
\hline \multirow[b]{2}{*}{ Study or Subgroup } & \multicolumn{3}{|c|}{$r L F+r F S H$} & \multicolumn{2}{|c|}{ rFSH only } & \multicolumn{3}{|r|}{ Mean Difference } & \multirow{2}{*}{$\begin{array}{l}\text { Mean Difference } \\
\text { IV. Fixed, } 95 \% \mathrm{Cl}\end{array}$} \\
\hline & Mean & SD & Total & Mean & SD & Total & Weight & IV. Fixed, $95 \% \mathrm{Cl}$ Year & \\
\hline Bosch et al., 2011 & 1,560 & 806 & 150 & 1,388 & 721 & 142 & $64.4 \%$ & $172.00[-3.21,347.21] 2011$ & \\
\hline König et al., 2013 & $1,777.7$ & $1,036.08$ & 125 & $1,399.4$ & 866.46 & 128 & $35.6 \%$ & $378.30[142.67,613.93] 2013$ & $\longrightarrow$ \\
\hline Total $(95 \% \mathrm{Cl})$ & & & 275 & & & 270 & $100.0 \%$ & $245.46[104.85,386.06]$ & \\
\hline \multicolumn{9}{|c|}{$\begin{array}{l}\text { Heterogeneity: } \mathrm{Chi}^{2}=1.90, \mathrm{df}=1(\mathrm{P}=0.17) ; \mathrm{I}^{2}=47 \% \\
\text { Test for overall effect: } Z=3.42(P=0.0006)\end{array}$} & $\begin{array}{ccccc}-1000 & -500 & 0 & 500 & 1000 \\
\text { Favours rLF+rFSH } & \text { Favours rFSH only }\end{array}$ \\
\hline
\end{tabular}

providing androgen substrate for aromatization, but also exerting a direct effect on the stimulation and modulation of folliculogenesis [24]. It is noticeable that both the theca cell and granulosa cell produce significant amount of progesterone, which was converted into androgens under the influence of $\mathrm{LH}$. Therefore, the $\mathrm{LH}$ supplementation resulted in the lower serum progesterone level. As is well established, increased exposure to progesterone can advance the endometrium, leading to asynchrony of embryo development to endometrial development and the reduction of implantation. Under this context, the LH supplementation may be beneficial for the serum oestradiol and progesterone level on the day of HCG administration.

As is predicted, our results suggested a beneficial effect of $\mathrm{r}$-LH supplementation on ovarian stimulation in serum oestradiol and progesterone level on the day of HCG administration in general population. However, there was no evidence of beneficial effect in ongoing pregnancy per ET; clinical pregnancy per ET; incidence of OHSS; r-FSH total dose used per treatment cycle; total days of stimulation per treatment cycle; number of retrieved oocytes per oocyte retrieval; number of mature oocytes (metaphase II) per oocyte retrieval; fertilization rate; implantation rate, which was in accordance with the result of the metaanalysis by Monique H Mochtar et al. (2010) [3].

With regard to LH supplementation for the advanced reproductive aged women undergoing IVF or ICSI with GnRH antagonist protocol, different trials showed different results. The study by Bosch et al. (2011) obtained a significantly better implantation rate and a clinically better ongoing pregnancy rate among those patients aged 36 to 39. However, the study by König et al. 2013 showed no benefit of LH supplementation in controlled ovarian stimulation for IVF/ICSI with GnRH antagonists on pregnancy rates in patients of 35 years or older. Then we pooled the data from the two trials, showing a significantly higher serum oestradiol level and significantly lower $r$-FSH total dose used per treatment cycle found in the combination of $\mathrm{r}-\mathrm{LH}$ with $\mathrm{r}-\mathrm{FSH}$ compared to $\mathrm{r}-\mathrm{FSH}$ alone for $\mathrm{COH}$ in advanced reproductive aged women undergoing IVF/ICSI with $\mathrm{GnRH}$ antagonist protocol. Although a significantly lower number of retrieved oocytes per oocyte retrieval was also found in the combination of $\mathrm{r}-\mathrm{LH}$ with $\mathrm{r}-\mathrm{FSH}$ group and the data of ongoing pregnancy or clinical pregnancy per ET were not available, we can not make the conclusion that LH supplementation was not beneficial for advanced reproductive aged women, since according to Bosch et al., the combination of $\mathrm{r}-\mathrm{LH}$ with $\mathrm{r}-\mathrm{FSH}$ group showed similar metaphase II oocytes and a better fertilization rate, thus suggesting that the oocytes obtained were of better quality, which would, in turn, lead to a higher implantation [14]. More trials and meta-analyses are needed to explore the role of LH supplementation played in advanced reproductive aged women.

Since oral contraceptive pills pretreatment is a convenient way for clinics to schedule oocyte retrievals, it will be more often applied by US clinics, although it is reported that oral contraceptive pills pretreatment

\begin{tabular}{|c|c|c|c|c|c|c|c|}
\hline Studv or Subgroup & $\begin{array}{c}\text { rLF+rFS } \\
\text { Mean SD }\end{array}$ & $\begin{array}{l}\text { H } \\
\text { Total }\end{array}$ & $\begin{array}{l}\text { rFSH onl } \\
\text { Mean SD }\end{array}$ & ly & Weight & $\begin{array}{l}\text { Mean Difference } \\
\quad \text { IV. Fixed, 95\% Cl Year }\end{array}$ & $\begin{array}{l}\text { Mean Difference } \\
\text { IV, Fixed, } 95 \% \mathrm{Cl}\end{array}$ \\
\hline Bosch et al., 2011 & $8.4 \quad 4.5$ & 150 & 10.16 .3 & 142 & $60.8 \%$ & $-1.70[-2.96,-0.44] 2011$ & $7-1$ \\
\hline König et al., 2013 & 10.26 .1 & 120 & $10.9 \quad 6.4$ & 123 & $39.2 \%$ & $-0.70[-2.27,0.87] 2013$ & $\longrightarrow+$ \\
\hline Total $(95 \% \mathrm{Cl})$ & & 270 & & 265 & $100.0 \%$ & $-1.31[-2.29,-0.32]$ & \\
\hline \multicolumn{7}{|c|}{$\begin{array}{l}\text { Heterogeneity: } \mathrm{Chi}^{2}=0.95, \mathrm{df}=1(\mathrm{P}=0.33) ; \mathrm{I}^{2}=0 \% \\
\text { Test for overall effect: } Z=2.61(P=0.009)\end{array}$} & 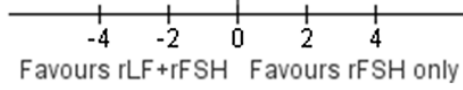 \\
\hline
\end{tabular}




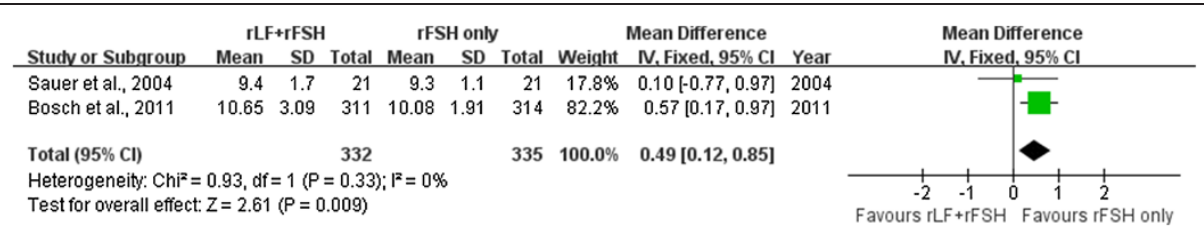

Figure 10 Forest plot of total days of stimulation per treatment cycle with or without $\mathrm{r}$-LH supplementation for $\mathrm{COH}$ in women undergoing IVF or ICSI-ET with GnRH antagonist protocol and oral contraceptive pills pretreatment.

diminishes the advantages of a $\mathrm{GnRH}$ antagonist protocol by extending the duration of treatment and the amount of FSH required to get to the same criteria of hCG [25], especially when stimulation is started immediately after OC withdrawal. This meta-analysis was not designed to detect a clinical relevant difference in ongoing pregnancy rate between pretreatment with or without oral contraceptive pills. Our results suggest a good effect of r-LH supplementation in ovarian stimulation in serum progesterone level on the day of HCG administration (WMD $-0.19,95 \%$ CI -0.25 to -0.13$)$. Significantly lower serum progesterone level was observed in the combination of r-LH with r-FSH group compared to r-FSH alone group for $\mathrm{COH}$ in women undergoing IVF or ICSI with GnRH antagonist protocol and oral contraceptive pills pretreatment. This might be due to the fact that oral contraceptive pills pretreatment could have had an influence on the endocrine environment in the follicular phase by means of endogenous gonadotropin control [26] and FSH acts on granulosa cells to facilitate the conversion of cholesterol into $\mathrm{P}$, which is transferred to the thecal cells to be converted into androgens under the action of $\mathrm{LH}$, therefore $\mathrm{LH}$ supplementation lowered serum progesterone level [27]. Moreover, lower progesterone level, subsequently, increased endometrium receptivity. Under this context, LH supplementation may be the optimal option by increasing the beneficial effect of $\mathrm{LH}$ administration in this particular population. Our results also show a significantly higher total days of stimulation per treatment cycle (WMD 0.49, 95\% CI 0.12 to 0.85 ) while significantly lower r-FSH total dose used per treatment cycle (WMD $-211.90,95 \%$ CI -319.99 to -103.82 ).

However, it has to be acknowledged that there still are some limitations in our meta-analysis. Firstly, the combined sample size of the five studies is still too small to confidentially detect a clinically relevant difference with regard to pregnancy likelihood between the two treatment modalities, especially when taking the subgroups into consideration, only the data from two or three trials were available for meta-analysis. Secondly, inclusion criteria of the selected trials were not as strict as possible, meaning that the inclusion criteria bias existed in the paper. For instance, when analyzing the outcomes of combination of $\mathrm{r}-\mathrm{LH}$ with $\mathrm{r}-\mathrm{FSH}$ comparing with $\mathrm{r}$ - $\mathrm{FSH}$ alone for $\mathrm{COH}$ in women undergoing IVF or ICSI with GnRH antagonist protocol in general population general population, all trials should be limited into those in which all the patients were pretreated with oral contraceptive pills or not, the initiation of LH supplementation was on the same stimulation day, and also ended on another same day, moreover, the initial dosage of FSH and LH was kept accordance with each trials. The last but not the least, the data of the trials was not all available for the meta-analysis, although the author was contacted if necessary, which resulted into that less trials were analyzed in the subgroup.

\section{Conclusions}

To conclude, the present meta-analysis found no statistically significant differences in outcomes of pregnancy between the combination of r-LH with r-FSH group and r-FSH alone group for $\mathrm{COH}$ with $\mathrm{GnRH}$ antagonist protocol in general population, in advanced reproductive aged women and in women pretreated with oral contraceptive pills undergoing IVF/ICSI. More studies are necessary for more solid conclusions on pregnancy likelihood after combination of r-LH with r-FSH for $\mathrm{COH}$ in $\mathrm{GnRH}$ antagonist protocol to be drawn.

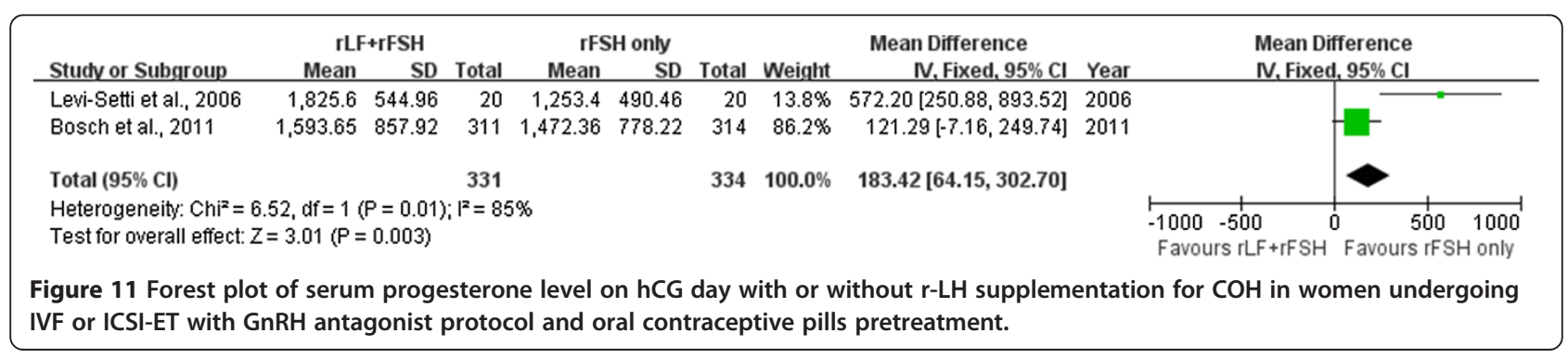




\section{Abbreviations}

ART: Assisted reproductive technology; Cl: Confidence intervals; $\mathrm{COH}$ : Controlled ovarian hyperstimulation; ET: Embryo transfer; $\mathrm{GnRH}$ : Gonadotropin-releasing hormone; hCG: human chorionic gonadotropin; ICSI: Intracytoplasmic sperm injection; IVF: In vitro fertilisation; OCP: oral contraceptive pill; OHSS: Ovarian hyperstimulation syndrome: OR: odds ratio; rFSH: Recombinant follicle-stimulating hormone; rLH: Recombinant luteinizing hormone; RTC: Randomized controlled trials; SD: standard deviation; WMD: weighted mean difference.

\section{Competing interests}

The authors declare that they have no competing interests.

\section{Authors' contributions}

YS was responsible for designing and coordinating the study. All authors were responsible for data collection, data analysis, and data interpretation $Y X$ and ZB were responsible for the statistical analysis and for writing the manuscript and contributed equally to this study. WD was responsible for reviewing the manuscript. All authors read and approved the final manuscript.

\section{Acknowledgements}

This work was supported by the National Natural Science Foundation of China (NO.31271605). The authors wish to thank the Medjaden Bioscience Limited experts for revising the English text.

Received: 12 August 2014 Accepted: 2 October 2014

Published: 24 November 2014

\section{References}

1. Albano C, Smitz J, Camus M, Riethmuller-Winzen H, Van Steirteghem A, Devroey P: Comparison of different doses of gonadotropin-releasing hormone antagonist Cetrorelix during controlled ovarian hyperstimulation. Fertil Steril 1997, 67:917-922.

2. Lindheim SR, Morales AJ: GnRH antagonists followed by a decline in serum estradiol results in adverse outcomes in donor oocyte cycles. Hum Reprod 2003, 18:2048-2051.

3. Mochtar $\mathrm{MH}$, der Veen $\mathrm{V}$, Ziech $\mathrm{M}$, van Wely M: Recombinant Luteinizing Hormone $(\mathrm{rLH})$ for controlled ovarian hyperstimulation in assisted reproductive cycles. Cochrane Database Syst Rev 2007, 2:CD005070.

4. Ferraretti AP, Gianaroli L, Magli MC, D'Angelo A, Farfalli V, Montanaro N: Exogenous luteinizing hormone in controlled ovarian hyperstimulation for assisted reproduction techniques. Fertil Steril 2004, 82:1521-1526.

5. Griesinger G, Schultze-Mosgau A, Dafopoulos K, Schroeder A, Schroer A, von Otte S, Hornung D, Diedrich K, Felberbaum R: Recombinant luteinizing hormone supplementation to recombinant follicle-stimulating hormone induced ovarian hyperstimulation in the $\mathrm{GnRH}$-antagonist multiple-dose protocol. Hum Reprod 2005, 20:1200-1206.

6. Sauer MV, Thornton MH 2nd, Schoolcraft W, Frishman GN: Comparative efficacy and safety of cetrorelix with or without mid-cycle recombinant $\mathrm{LH}$ and leuprolide acetate for inhibition of premature LH surges in assisted reproduction. Reprod Biomed Online 2004, 9:487-493.

7. Levi-Setti PE, Cavagna M, Bulletti C: Recombinant gonadotrophins associated with $\mathrm{GnRH}$ antagonist (cetrorelix) in ovarian stimulation for ICSI: comparison of r-FSH alone and in combination with r-LH. Eur J Obstet Gynecol Reprod Biol 2006, 126:212-216.

8. Lisi F, Rinaldi L, Fishel S, Caserta D, Lisi R, Campbell A: Evaluation of two doses of recombinant luteinizing hormone supplementation in an unselected group of women undergoing follicular stimulation for in vitro fertilization. Fertil Steril 2005, 83:309-315.

9. Matorras R, Prieto B, Exposito A, Mendoza R, Crisol L, Herranz P, Burgues S: Mid-follicular LH supplementation in women aged 35-39 years undergoing ICSI cycles: a randomized controlled study. Reprod Biomed Online 2009, 19:879-887.

10. Baruffi RL, Mauri AL, Petersen CG, Felipe V, Martins AM, Cornicelli J, Cavagna M, Oliveira JB, Franco JG Jr: Recombinant LH supplementation to recombinant FSH during induced ovarian stimulation in the $\mathrm{GnRH}$ antagonist protocol: a meta-analysis. Reprod Biomed Online 2007, 14:14-25.

11. Youssef MA, Van der Veen F, Al-Inany HG, Griesinger G, Mochtar MH, van Wely M: Gonadotropin-releasing hormone agonist versus HCG for oocyte triggering in antagonist assisted reproductive technology cycles. Cochrane Database Syst Rev 2010, 1:CD008046.

12. Wong PC, Qiao J, Ho C, Ramaraju GA, Wiweko B, Takehara Y, Nadkarni PV, Cheng LC, Chen HF, Suwajanakorn S, Vuong TN: Current opinion on use of luteinizing hormone supplementation in assisted reproduction therapy: an Asian perspective. Reprod Biomed Online 2011, 23:81-90.

13. Hill MJ, Levens ED, Levy G, Ryan ME, Csokmay JM, DeCherney AH, Whitcomb BW: The use of recombinant luteinizing hormone in patients undergoing assisted reproductive techniques with advanced reproductive age: a systematic review and meta-analysis. Fertil Steril 2012, 97:1108-1114. e1101.

14. Bosch E, Labarta E, Crespo J, Simon C, Remohi J, Pellicer A: Impact of luteinizing hormone administration on gonadotropin-releasing hormone antagonist cycles: an age-adjusted analysis. Fertil Steril 2011, 95:1031-1036.

15. Konig TE, van der Houwen LE, Overbeek A, Hendriks ML, Beutler-Beemsterboer SN, Kuchenbecker WK, Renckens CN, Bernardus RE, Schats R, Homburg R, Homburg R, Hompes PG, Lambalk CB: Recombinant LH supplementation to a standard $\mathrm{GnRH}$ antagonist protocol in women of 35 years or older undergoing IVF/ICSI: a randomized controlled multicentre study. Hum Reprod 2013, 28:2804-2812.

16. Diedrich K, Diedrich C, Santos E, Zoll C, Al-Hasani S, Reissmann T, Krebs D, Klingmuller D: Suppression of the endogenous luteinizing hormone surge by the gonadotrophin-releasing hormone antagonist Cetrorelix during ovarian stimulation. Hum Reprod 1994, 9:788-791.

17. Olivennes F, Alvarez S, Bouchard P, Fanchin R, Salat-Baroux J, Frydman R: The use of a $\mathrm{GnRH}$ antagonist (Cetrorelix) in a single dose protocol in IVF-embryo transfer: a dose finding study of 3 versus $2 \mathrm{mg}$. Hum Reprod 1998, 13:2411-2414.

18. Damario MA, Barmat L, Liu HC, Davis OK, Rosenwaks Z: Dual suppression with oral contraceptives and gonadotrophin releasing-hormone agonists improves in-vitro fertilization outcome in high responder patients. Hum Reprod 1997, 12:2359-2365.

19. O'Dea L, O'Brien F, Currie K, Hemsey G: Follicular development induced by recombinant luteinizing hormone $(\mathrm{LH})$ and follicle-stimulating hormone (FSH) in anovulatory women with LH and FSH deficiency: evidence of a threshold effect. Curr Med Res Opin 2008, 24:2785-2793.

20. Vaskivuo TE, Tapanainen JS: Apoptosis in the human ovary. Reprod Biomed Online 2003, 6:24-35.

21. Fortune JE, Voss AK: Oxytocin gene expression and action in bovine preovulatory follicles. Regul Pept 1993, 45:257-261.

22. Brown JB: Pituitary control of ovarian function-concepts derived from gonadotrophin therapy. Aust N Z J Obstet Gynaecol 1978, 18:46-54.

23. Loumaye E, Engrand P, Shoham Z, Hillier SG, Baird DT: Clinical evidence for an LH 'ceiling' effect induced by administration of recombinant human LH during the late follicular phase of stimulated cycles in World Health Organization type I and type II anovulation. Hum Reprod 2003, 18:314-322.

24. Filicori M, Cognigni GE, Taraborrelli S, Spettoli D, Ciampaglia W, Tabarelli De Fatis C, Pocognoli P, Cantelli B, Boschi S: Luteinzing hormone activity in menotropins optimizes folliculogenesis and treatment in controlled ovarian stimulation. J Clin Endocrinol Metab 2001, 86:337-343.

25. Rombauts L, Healy D, Norman RJ: A comparative randomized trial to assess the impact of oral contraceptive pretreatment on follicular growth and hormone profiles in $\mathrm{GnRH}$ antagonist-treated patients. Hum Reprod 2006, 21:95-103

26. Huirne JA, Homburg R, Lambalk CB: Are GnRH antagonists comparable to agonists for use in IVF? Hum Reprod 2007, 22:2805-2813.

27. Adonakis G, Deshpande N, Yates RW, Fleming R: Luteinizing hormone increases estradiol secretion but has no effect on progesterone concentrations in the late follicular phase of in vitro fertilization cycles in women treated with gonadotropin-releasing hormone agonist and follicle-stimulating hormone. Fertil Steril 1998, 69:450-453.

\section{doi:10.1186/1477-7827-12-109}

Cite this article as: Xiong et al:: Recombinant luteinizing hormone supplementation in women undergoing in vitro fertilization/ intracytoplasmic sperm injection with gonadotropin releasing hormone antagonist protocol: a systematic review and meta-analysis. Reproductive Biology and Endocrinology 2014 12:109. 